\title{
Das figuras que habitam as dramaturgias modernas e contemporâneas
}

Nayara Macedo Barbosa de Brito ${ }^{1}$ 


\section{Resenha da obra:}

RYNGAERT, Jean-Pierre; SERMON, Julie. Le personnage théâtral contemporain: décomposition, recomposition. Montreuil: Éditions Theatrales, 2006.

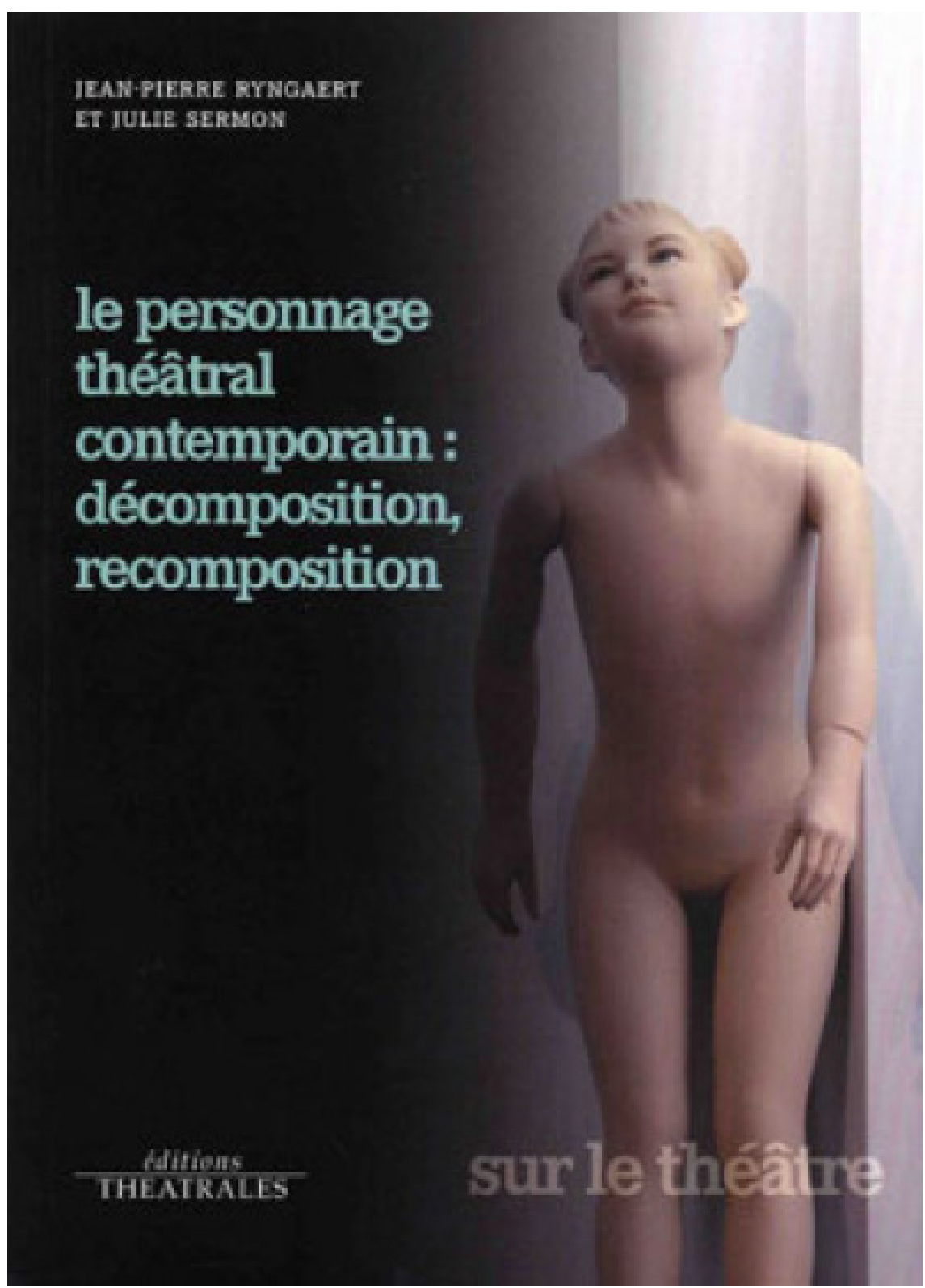

Em 2006, Jean-Pierre Ryngaert e Julie Sermon reuniram suas pesquisas em torno da personagem moderna e contemporânea no livro Le personnage théâtral contemporain: décomposition, recomposition. Neste volume, os autores atualizam as discussões já publicadas sobre o tema, notadamente aquela pioneira empreendida por Robert Abirached em 1978 e intitulada La crise du personnage dans le théâtre modern e a desenvolvida por Elinor Fuchs em 1996 sob o título The death of character: perspectives on theatre after modernism. 
Dando sequência às reflexões já expostas por Ryngaert no seu conhecido Ler o teatro contemporâneo (de 1993, traduzido e publicado no Brasil em 1998), a discussão aqui enfatiza a questão da personagem a partir do diálogo que o autor estabelece com Julie Sermon, pesquisadora de quem orientou a tese de doutoramento L'Effet-figure: états troublés du personnage contemporain (Lagarce, Minyana, Novarina, Renaude), de 2004.

O termo "figura", aliás, tomado da ideia de "figural" desenvolvida por Gilles Deleuze e utilizado por Sermon em sua tese é, nesta publicação, uma das maiores contribuições teóricas dadas pelos autores. Convocado pela necessidade de uma renovação lexical demandada por uma série de dramaturgias escritas a partir do século XX, o termo é utilizado para se referir aos seres ficcionais que "escapam da influência da palavra 'personagem' ao questionarem seus pressupostos [aristotélico-hegelianos] ou frustrá-los"2 (Ryngaert; Sermon, 2006, p. 10).

Como os autores observam, seu uso provoca mudanças significativas na compreensão do que seja a personagem de teatro: se ela é considerada uma entidade substancial, pré-existente à representação, ao acontecimento cênico, a figura é entendida como uma forma de aparição que até pode adquirir alguma substância no decorrer da cena, mas que só existe nela e cujo aspecto mais interessante é a forma como aparece em cena e na relação com os demais elementos que a compõem. Surgida com os autores do chamado Novo Romance (Marguerite Duras, Samuel Beckett, Nathalie Sarraute, etc.), essas figuras seriam o resultado da expulsão dos "efeitos de real através dos quais, tradicionalmente, o personagem [...] [vinha funcionando] como lente convergente da ilusão". Ao "impersonalizá-lo", os autores tornam-no menos um fantoche do que "uma presença anônima [...] atravessada por falas" ${ }^{\text {(Ryngaert; }}$ Sermon, 2006, p. 60-1).

No parágrafo introdutório, os teóricos localizam sua discussão numa perspectiva de superação da ideia de morte da personagem, corolária da morte do próprio drama, conforme uma dada linha de pensamento representada por teóricos como Theodor Adorno (1984) e Hans-Thies Lehmann (2007). Para Ryngaert e Sermon, “Longe de ser mortífera, a crise do personagem se tornou, nas escrituras modernas e contemporâneas, um dos signos de sua vitalidade"4 (2006, p. 7). Trata-se, então, de uma abordagem, como os próprios autores afirmam, otimista, uma vez que aponta não para um estado de decomposição (pós-dramática), mas de recomposição, em novas bases, da personagem teatral.

A abordagem metodológica empregada por eles propõe pensar a personagem a partir de algumas categorias/pontos de referência dramatúrgicos, tais como identidade, ação, espaço, temporalidade, fala, constelação de personagens, tipologia, etc. Para tanto, Ryngaert e Sermon lançam mão de uma série de peças, em sua maioria de autoras/es franceses - a exemplo de Noëlle Renaude, Michel Vinaver e Daniel Danis -, nas quais identificam e discutem as categorias levantadas.

\footnotetext{
2 "[...] des êtres de fiction qui échappent à l'emprise du mot 'personnage', parce qu'ils en remettent en cause les présupposés ou les déjouent". (Todas as traduções neste texto são de nossa autoria).

3 “[...] 'effets de réel' par lequels, traditionnellement, le personnage [...] comme lentille convergente de l'illusion vraisemblable".

"[...] l'impersonnaliser'[...] une présence anonyme [...] traversé de paroles".

4 "Loin d'être mortifère, la 'mise en crise' du personnage est ainsi devenue, dans les écritures modernes et contemporaines, l'un des signes de sa vitalité".
} 
No segundo capítulo, "Identificar o personagem", os autores atentam para os nomes com que os dramaturgos vêm batizando suas personagens, sendo esses nomes, já de entrada, reveladores das relações construídas ao longo das peças. Retomam aí a reflexão sobre as listas de indicação das personagens normalmente presentes no início dos textos, sobre o que comentaram no capítulo anterior: eles observam como a lógica operada nas dramaturgias ditas tradicionais, na qual a lista reflete o sistema actancial da própria peça que introduz, ordenando as personagens de acordo com sua importância na fábula, dá lugar a uma organização segundo a ordem de entrada das personagens em cena; assim, ao invés de esboçar a fábula, a lista "simula, como numa leitura acelerada, o curso da representação. [...] [Dando vasão à] passagem [...] de uma lógica narrativa (primado da ação) a uma lógica enunciativa (primado do discurso)"5 (Ryngaert; Sermon, 2006, p. 50-1), que é, enfim, mais característica das dramaturgias que estão discutindo.

É observando essa tendência que os autores desenvolvem o capítulo seguinte, "A personagem e sua fala", onde situam a emergência desse teatro em que "toda a atenção se coloca sobre o ato da enunciação"6 (Ryngaert; Sermon, 2006, p. 82) num contexto epistemológico no qual, em diferentes áreas do conhecimento, demonstrou-se que a fala não deve ser compreendida como um mero veículo de transmissão de informações objetivas, mas, antes, interpretada em função dos referentes simbólicos e do imaginário no qual está inserida. Desse modo, a fala é entendida enquanto uma atividade, uma represent(ação) no/do mundo. Substitui-se "a lógica narrativa do personagem clássico [leia-se, da tradição aristotélico-hegeliana], construída e confirmada pelo diálogo, por uma poética de identidades performativas"7 (2006, p. 84), cujas falas são caracterizadas principalmente pela heterogeneidade de formas e de fontes enunciadoras.

No início do quarto capítulo, "Imagem, imaginário, encarnação", os autores colocam em questão o caráter metonímico e representativo da personagem conforme entendida tradicionalmente, argumentando com o fato de que há pelo menos "um século o teatro perdeu a exclusividade da ficção animada"8 (Ryngaert; Sermon, 2006, p. 109). Propõem, então, repensarmos o lugar que o fazer teatral ocupa ou pode ou deve ocupar na sociedade contemporânea e sabermos "o que querem dizer, hoje, os modos de aparição e de jogo próprios ao personagem e a seus processos de decomposição-recomposição", "que papeis e que estatutos pode ainda pretender, sobre a cena, o personagem contemporâneo"9 (ibidem.). Para auxiliar na reflexão, discutem conceitos como os de persona, máscara, rosto, figura e personagem pós-dramática, além da diferença entre o que chamam, a partir dos estudos da filósofa Marie-José Mondzain, de "imagens que encarnam" e "imagens que incorporam".

\footnotetext{
5 "[...] simule, comme en lecture accélérée, le cours de la répresentation, [...] passage [...] d'une logique narrative (primat de l'action) à une logique énonciative (primat de la prise de parole) [...]".

6 "[...] tout l'attention se porte sur l'acte d'énoncer au présent".

7 '[...] substituent en effet à la logique narrative du personnage classique, construit et confirmé au fil du dialogue, une poétique d'indentités performatives [...]”.

8 "[...] plus d'un siècle que le théâtre a perdu l'exclusivité de la fiction animée, [...]".

9 "[...] ce que veulent dire, aujourd'hui, les modes d'apparition et de mise en jeu propres au personnage et à ses procès de décomposition-recomposition". "[...] à quels rôles et quels status peut encore prétendre, sur scéne, le personnage contemporain."
} 
No capítulo seguinte, "A personagem e seu leitor", refletem sobre a transformação operada por essas dramaturgias na relação entre esses dois elementos. Questionam como o leitor/a leitora tem se interessado pelas figuras presentes nesses textos, das quais pouquíssimas informações são dadas. Para os autores, essa economia de informações implica a radicalização da função da leitora/leitor, a quem cabe se envolver mais afetiva e intelectualmente e criar, se for de seu interesse, a identidade da personagem em questão, a partir dos dados que lhes são oferecidos e de seu próprio imaginário.

Enfim, no último capítulo os autores tratam daquela que talvez seja a relação mais desafiada por essas dramaturgias, a d'“O ator [atriz] e o personagem". Relação pouco problematizada entre os teóricos da linhagem de Ryngaert e Sermon, em especial do grupo de pesquisa do qual fazem parte ${ }^{10}$, neste livro os autores chegam a esboçar algumas das dificuldades e desafios com os quais a/o intérprete se depara ao decidir levar essas dramaturgias à cena.

Segundo os autores, as marcas gráficas apresentadas formal e visualmente nos textos e os jogos linguísticos ali encontrados, já de saída desestabilizando o ator/atriz, parecendo convidá-la/lo a uma leitura técnica e não hermenêutica dos enunciados. Marcadas predominantemente pelo verso livre, essas dramaturgias fazem com que as palavras obedeçam não apenas a uma lógica de raciocínio, mas também de ressonância, "um dos ofícios do ator contemporâneo [sendo] talvez [o de] fazer-nos surpreender novamente com a fala"11 (Ryngaert; Sermon, 2006, p. 159).

Ainda sobre essa questão, entre outros pontos levantados, os autores indicam dois modelos de interpretação que ocupariam posições polares nesse contexto: o do realismo-naturalismo, que poderia (e pode) ser imposto a despeito das particularidades dessas dramaturgias; e outro em que a atriz/o ator se deixaria atravessar pelas qualidades rítmicas e fonéticas do texto. Segundo eles, nenhum desses modelos parece convir ao caráter fragmentário desses textos; no entanto, afirmam mais à frente que

privado dos apoios que lhe permitiam tradicionalmente construir e balizar seu jogo (intencionalidade, emoção, racionalidade do personagem conhecido como carácter), o ator deve passar pela voz do texto para interpretar esses personagens. Não preexistindo às palavras que pronunciam, as figuras não são outra coisa que o que elas dizem. ${ }^{12}$ (Ryngaert; Sermon, 2006, p. 163)

Le personnage théâtral contemporain: décomposition, recomposition, ainda não traduzido para o português e apresentado ao leitor/leitora brasileira/o, apesar de publicado há 12 anos, permanece sendo um importante estudo para quem quer compreender as dinâmicas operadas pelas dramaturgias ditas contemporâneas e as implicações que elas vêm provocando na cena e no público.

\footnotetext{
${ }^{10}$ Referimo-nos ao Grupo de Pesquisa sobre a Poética do Drama Moderno e Contemporâneo (Universidade Sorbonne Nouvelle - Paris III).

11 "L'un des offices de l'acteur contemporain est peut-être de nous réapprendre à nous étonner de la parole".

12 "[...] privé des appuis qui lui permettent traditionnellement de construire et de jalonner son jeu (l'intentionnalité, l'émotion, la rationalité du personnage conçu comme caractère), l'acteur doit en passer par la voix du texte pour interpréter ces personnagens. Ne préexistant pas aux mots qu'elles prononcent, les figures ne sont rien d'autre que ce qu'elles disent".
} 


\section{Referências}

ADORNO, Theodor. Pour comprendre "Fin de partie". In: Notes sur la littérature. Paris: Flammarion, 1984.

LEHMANN, Hans-Thies. Teatro pós-dramático. Trad. Pedro Süssekind. São Paulo: Cosac \& Naify, 2007.

RYNGAERT, Jean-Pierre; SERMON, Julie. Le personnage théâtral contemporain: décomposition, recomposition. Montreuil: Éditions Theatrales, 2006.

Recebido em: 23/09/2018 Aprovado em: 22/10/2018 